\title{
Gender, Social Support, and Posttraumatic Stress in Postwar Kosovo
}

\author{
Jennifer Ahern, MPH, * Sandro Galea, MD, DrPH, *† William G. Fernandez, MD, MPH, †t \\ Bajram Koci, MD, MS, \& Ronald Waldman, MD, MPH, † and David Vlahov, PhD*广
}

\begin{abstract}
The effects of social support and traumatic experiences on mental health in conflict situations may be different by gender. The Kosovo Emergency Department Study was conducted in July and August 2001 to assess mental health 2 years after the end of the war in Kosovo. Of 306 emergency department patients $(87.7 \%$ response rate), all were ethnic Albanian, 97.4\% had experienced traumatic events, and $89.5 \%$ had posttraumatic stress symptoms. Women and persons who experienced more traumatic events had higher posttraumatic stress scores. Persons with social support had lower posttraumatic stress scores. In a final model, social support had a greater protective effect for women, whereas traumatic events had a greater detrimental effect on men. Two years after the war in Kosovo, there remained a high prevalence of posttraumatic stress symptoms, particularly among women with low social support. Interventions targeting social support may be important public health efforts in the postwar context.
\end{abstract}

Key Words: Gender, social support, posttraumatic stress, war, trauma, Kosovo.

( J Nerv Ment Dis 2004;192: 762-770)

In March 1999, the North Atlantic Treaty Organization began bombing Kosovo in an attempt to force the Serbian government to end the escalating Serbian-Albanian conflict. The bombing ended in June 1999, and Serbia accepted the terms of the peace accord. However, the situation in Kosovo

*Center for Urban Epidemiologic Studies, New York Academy of Medicine, New York, New York; †Joseph L. Mailman School of Public Health, Columbia University, New York, New York; †Division of Emergency Medicine, New York Presbyterian Hospital, New York, New York; and $\S$ Department of Anesthesia, Section of Emergency Medicine, University of Pristina Medical Center, Pristina, Kosovo.

Supported in part by a development grant from the Program on Forced Migration, Heilbrunn Center for Population and Family Health, Joseph L. Mailman School of Public Health, Columbia University.

Send reprint requests to Sandro Galea, MD, DrPH, Center for Urban Epidemiologic Studies, New York Academy of Medicine, 1216 5th Avenue, Room 553, New York, NY 10029.

Copyright (C) 2004 by Lippincott Williams \& Wilkins

ISSN: 0022-3018/04/19211-0762

DOI: $10.1097 / 01 . n m d .0000144695 .02982 .41$ has remained tense since, with ongoing ethnic segregation and violence (United Nations Security Council, 2001). Most residents of Kosovo experienced traumatic events during the years of conflict leading up to, during, and after the bombing, many of which split families apart through forced separation, imprisonment, displacement, and death (Cardozo et al., 2000). In a culture in which the family units are strong and family members provide social support for one another (Agani, 2001), such disruption of families may have devastating effects on mental health well beyond the end of the conflict. In this article, we explore the effects of war events and social support on posttraumatic stress 2 years after the end of the conflict in Kosovo in an emergency department population. We additionally assess gender differences in the associations between war events, social support, and posttraumatic stress.

Traumatic events are associated with mental health symptoms in many different contexts (Cardozo et al., 2000; de Jong et al., 2001; Kessler et al., 1995). Assaultive traumas such as physical attacks, sexual assault, and combat situations generally have the strongest associations with psychological problems (Breslau et al., 1999; Cardozo et al., 2000; Kessler et al., 1995). Recent research has shown that mental health symptoms are substantial in the general population after war. For example, the prevalences of posttraumatic stress disorder (PTSD) among civilians in Algeria, Cambodia, Ethiopia, and Gaza ranged from $15.8 \%$ to $37.4 \%$ after various wars and conflicts (de Jong et al., 2001). In Sri Lanka, $27.5 \%$ of a civilian sample had PTSD during an ongoing civil war (Somasundaram and Sivayokan, 1994). A study of Kosovar Albanians 1 month after the end of the NATO bombing found the prevalence of PTSD to be $17.1 \%$ in the general population (Cardozo et al., 2000).

Several studies suggest that among women and men experiencing the same traumatic events, there are more psychological sequelae of the traumatic experience among women (Breslau et al., 1999; Brewin et al., 2000; Kessler et al., 1995). In one study, among women and men who had been threatened with a weapon, $32.6 \%$ of women and $1.9 \%$ of men had PTSD ( $p<.05$; Kessler et al., 1995). In particular, there is evidence that assaultive trauma has a greater effect on 
women than it does on men (Breslau et al., 1999; Stein, 2000). In a study by Breslau et al. (1999), the prevalence of PTSD among persons who had experienced assaultive violence (including combat, rape, held captive, shot/stabbed, sexual assault, mugged, beaten up) was $35.7 \%$ among women and $6.0 \%$ among men $(p<.001)$. In addition, women may experience more events during their lives that have a greater traumatic effect (Kessler et al., 1995). In a nationally representative United States sample, $60.7 \%$ of men had experienced any lifetime trauma, compared with $51.2 \%$ of women; however, $67.6 \%$ of women experienced a trauma associated with a high probability of PTSD, compared with $44.6 \%$ of men (Kessler et al., 1995). These two gender differences, first in the psychological reaction to the same events and second in the severity of events experienced, may account for the high prevalence of mental health problems after traumatic event experiences documented among women.

However, research in the context of war does not consistently suggest a greater effect of traumatic events on women (Cardozo et al., 2000; Dahl et al., 1998; Dybdahl, 2001; Kunovich, 1999). In the aforementioned Kosovo study, performed soon after the war, the prevalence of PTSD was $19.7 \%$ among women and $12.0 \%$ among men (Cardozo et al., 2000). Both female gender and number of traumatic events experienced were significant predictors of PTSD in multivariable analysis, but the effect of traumatic events was not examined separately by gender (Cardozo et al., 2000). A study of displaced Bosnian women found that the number of traumatic war events experienced was not associated with PTSD symptoms (Dybdahl, 2001). Another study of Bosnian women found that the number of war events was not associated with PTSD, although the most severe stressors, including confinement to a concentration camp and rape, were associated with PTSD (Dahl et al., 1998). A study of the association between fighting in the war and distress among Croatians showed a strong effect of fighting on distress among men and a weak association among women (Kunovich, 1999). Although situational differences in the conflicts may explain the seemingly inconsistent findings, variability in other determinants of mental health may be partly responsible for these differences.

Social support may offer important protection for mental health in the context of traumatic events, including the trauma of war (Berkman et al., 2000; Kawachi and Berkman, 2001; Sherbourne and Stewart, 1991). In diverse nonwar settings, studies have shown the protective effects of social support for mental health (Olstad et al., 2001; Silveira and Ebrahim, 1998; Viinamaki et al., 1995). For example, a Norwegian study demonstrated a longitudinal buffering effect of social support and social networks against the mental health effects of a wide range of acute and chronic stressors (Olstad et al., 2001). In the context of war, a study of Israeli soldiers in locations that were bombed during the Gulf War showed that low social support was associated with psycho- logical distress (Solomon et al., 1991). Social support was also protective against PTSD among former prisoners of war (Engdahl et al., 1997). A study among Bosnian refugees found that social isolation was associated with PTSD (Miller et al., 2002). Among Vietnamese refugees who had experienced traumatic war experiences, low social support and separation from close family were both associated with psychiatric disorders (Hauff and Vaglum, 1995).

There also may be gender differences in the importance of social relationships and social support for mental health (Kawachi and Berkman, 2001). General population studies suggest that social supports and networks may be more important for women's mental health (Bultmann et al., 2002; Kawachi and Berkman, 2001; Olstad et al., 2001). In the context of war, the results are somewhat mixed (Dybdahl, 2001; Farhood et al., 1993; Green and Berlin, 1987; King et al., 1999). Social support was protective against PTSD symptoms among displaced Bosnian women (Dybdahl, 2001), whereas a study of families in Lebanon showed that social support was more important for fathers' mental, physical and interpersonal well being than it was for mothers' well being (Farhood et al., 1993). A study of Vietnam veterans showed that among male veterans, war zone stressors were the largest contributors to PTSD symptomatology, whereas among female veterans, postwar factors including social support were the largest predictors (King et al., 1999). In a study of male Vietnam veterans, social support was not associated with PTSD symptoms (Green and Berlin, 1987). The mixed results on gender differences in the importance of social support may be explained in part by situational differences, combatant versus civilian involvement, and the ways that culture-specific gender roles are affected by the conflict situations.

In light of previous research on gender, social support, traumatic events, and their relations with psychological symptoms, we formulated three research questions. Two years after the war in Kosovo, a) are there gender differences in posttraumatic stress symptoms, social support, or traumatic events experienced? b) are gender, social support and traumatic events associated with posttraumatic stress symptoms? and c) are there interactions between gender, social support, and traumatic events in association with posttraumatic stress symptoms? In terms of interactive effects, we were interested in whether the effect of social support on posttraumatic stress symptoms was different for women than it was for men, whether the effect of traumatic events was different for women than for men, and whether the effect of traumatic events was different depending on the level of social support.

\section{METHODS}

\section{Data Collection}

We conducted the Kosovo Emergency Department Study in July and August 2001 at the University of Pristina 
Medical Center Emergency Department in Pristina, Kosovo. Every sixth patient who was not critically ill and was able to consent was approached for participation in the study; participants provided written informed consent and then completed an anonymous self-administered questionnaire in a private room with researcher assistance as necessary. This study was approved by the Institutional Review Boards of Columbia University and the University of Pristina.

\section{Measures}

The study instrument was a structured questionnaire in Albanian (translated and back-translated) that included questions on demographic characteristics, behaviors, current residence, displacement during the war, employment, and access to health care.

\section{Social Support}

We measured social support with a modified version of the Medical Outcomes Study social support scale (Sherbourne and Stewart, 1991), which included instrumental support (e.g., someone to help if you were confined to bed), emotional support (e.g., someone to talk to if you were upset, nervous, or depressed) and appraisal support (e.g., someone you could turn to for advice). Responses were recorded on a Likert scale with the choices of "definitely not," "probably not," "probably yes," and "definitely yes" assigned values from 1 to 4 . The mean of responses to all social support items constituted the social support scale.

\section{Traumatic Events}

Traumatic events experienced were measured with the Harvard Trauma Questionnaire (HTQ; Mollica et al., 1992). The HTQ assesses traumatic events commonly experienced in war situations. For each event, participants were asked to indicate whether they had experienced, witnessed, or heard of the event and to indicate all that applied. The traumatic events included being in a combat situation, lack of food or water, lack of shelter, ill health without access to medical care, forced separation of family members, being close to death, torture, forced isolation, family member or self involved in fighting, murder of family or friend, unnatural death of family or friend, serious injury, imprisonment, murder of stranger or strangers, lost or kidnapped, rape or sexual assault, and other frightening or life-endangering situation. A sum of events experienced was created for this analysis.

\section{Posttraumatic Stress}

The HTQ was also used to assess posttraumatic stress symptoms. The first 16 items were based on the DSM-III-R PTSD symptoms experienced in the past week. An additional 14 items assessed other mental health symptoms commonly found among refugees. Respondents were asked whether they were bothered by each symptom "not at all," "a little," "quite a bit," or "extremely" in the past week, with responses coded from 1 to 4. A posttraumatic stress score was created using the mean of responses to the DSM-III-R PTSD items, creating a scale ranging from 1 to 4 . The resulting score summarizes how much respondents were bothered on average by PTSD symptoms over the past week. The HTQ was originally developed for and validated among Indochinese refugees (Mollica et al., 1992). In this validation study, the interrater reliability was 0.98 , and the test-retest reliability with a 1 -week interval was 0.92 . In comparison with physician diagnosis of PTSD, the sensitivity of the HTQ scale (using a cutoff score of 2.5 ) was $78 \%$, and the specificity was $65 \%$. The HTQ was more accurate than the Hopkins Symptom Checklist (Mollica et al., 1987) in identifying physiciandiagnosed PTSD cases. Subsequently, a study among Bosnian refugees suggested the use of DSM-III-R criteria for PTSD from the HTQ to classify PTSD (instead of the cutoff score of 2.5). This decision was made because a cutoff in the HTQ corresponding to a psychiatric diagnosis of PTSD had not been established in the study population (Mollica et al., 1999). The use of DSM-III-R criteria in this population correlated well with the standard 2.5 cutoff and was more conservative in classifying PTSD (Mollica et al., 1999). Based on this recommendation, we created our measure of probable PTSD in the same manner (based on the DSM-III-R criteria) by requiring one re-experiencing (e.g., recurrent thoughts or memories of the most hurtful or terrifying events), three avoidance (e.g., avoiding activities that remind you of the traumatic or hurtful event), and two arousal (e.g., feeling jumpy, easily startled) symptoms bothering the respondent "quite a bit" or "extremely" in the past week (Cardozo et al., 2000; Mollica et al., 1992).

\section{Statistical Analysis}

Gender differences in posttraumatic stress scores, probable PTSD, social support, and traumatic events were assessed with $\chi^{2}$ and $t$-tests. For each scale, the items composing the scale were examined individually by gender to assure that summing and averaging items into scales would not mask important gender differences in exposures or outcomes. For regression analysis, we examined both probable PTSD and the posttraumatic stress score as outcomes; because the conclusions from both analyses were the same, the results for posttraumatic stress scores are presented because a continuous outcome provides more power with a small sample. Bivariate linear regression was used to assess individually the effects of gender, social support, and traumatic events on the posttraumatic stress score. A multivariable linear regression model was used to assess the effects of gender, social support, and traumatic events on posttraumatic stress symptoms. Finally, we assessed interaction between gender, social support, and traumatic events in relation to posttraumatic stress with the addition of interaction terms to the linear regression 
model and the use of $F$-tests to assess improvement in model fit. Predicted posttraumatic stress scores were calculated from the final model because parameter estimates are not individually interpretable in the presence of interactions. For predicted scores, few traumatic events was operationalized as one event reported, and many events as 13 reported. Low social support was operationalized as a score of 1 on the scale, and high social support as a score of 4 . These values were selected as they represent the range of the values for these characteristics in the data set.

\section{RESULTS}

There were 306 participants out of 349 persons approached ( $87.7 \%$ response rate). All respondents were ethnic Albanian and had been born in Kosovo. Approximately 63\% were male, mean age was 39 (range, 17-87), 69.5\% were married, and $50.5 \%$ had less than a high school education. More than $97 \%$ of respondents reported experiencing at least one traumatic event, and $89.5 \%$ reported any current posttraumatic stress symptoms. A complete description of the study sample can be found in Table 1 .

The mean posttraumatic stress score was 2.00 (range, $1-4)$; the scale had a Cronbach's $\alpha$ of 0.86 . A score of 2.00 means that on average, respondents were bothered "a little" by posttraumatic stress symptoms in the past week. The overall prevalence of probable PTSD was $14.1 \%$. The social support scale had had a Cronbach's $\alpha$ of 0.90 , and the mean score was 3.04 (range, 1-4), reflecting that on average, there was "probably" someone to help with the scenarios presented. The mean number of traumatic events experienced was 6.62 (range, $0-13$ ).

Examining these scales by gender, women had higher posttraumatic stress scores than men (2.13 for women, 1.93 for men; $p=.002$ ). Examining the individual items of the posttraumatic stress scale by gender, women scored higher on all items except for "feeling on guard," suggesting that the creation of a scale was not masking any major difference in posttraumatic stress symptoms experienced. When measured as probable PTSD, women had a higher prevalence than men ( $17.0 \%$ for women, $12.4 \%$ for men; $p=.27$ ), although this difference was not statistically significant. Women and men had very similar social support scores (3.08 for women, 3.01 for men; $p=.30)$ and numbers of traumatic events experienced (6.54 for women, 6.66 for men; $p=.74$ ). There were some differences in the specific traumatic events experienced by gender (Table 2). Men reported experiencing "imprisonment" and "serious injury" more often $(17.6 \%$ and $18.6 \%$ respectively) than women ( $2.7 \%$ and $4.6 \%$, respectively). Women reported experiencing "lack of shelter" (73.6\%) more frequently than men $(60.8 \%)$.

In bivariate linear regression, female gender was associated with a higher posttraumatic stress score $(\beta=0.19$; intercept $=1.93 ; p=.002)$; the number of traumatic events
TABLE 1. Demographic Characteristics, Kosovo Emergency Department Study, 2001

\begin{tabular}{|c|c|c|}
\hline Characteristic & $N$ & $\%$ \\
\hline Total & 306 & 100.0 \\
\hline \multicolumn{3}{|l|}{ Gender } \\
\hline Male & 194 & 63.4 \\
\hline Female & 112 & 36.6 \\
\hline \multicolumn{3}{|l|}{ Education } \\
\hline High school graduate or more & 151 & 49.5 \\
\hline Less than high school & 154 & 50.5 \\
\hline \multicolumn{3}{|l|}{ Current employment } \\
\hline Yes & 96 & 31.6 \\
\hline No & 208 & 68.4 \\
\hline \multicolumn{3}{|l|}{ Ethnicity } \\
\hline Albanian & 306 & 100.0 \\
\hline \multicolumn{3}{|l|}{ Marital status } \\
\hline Married & 201 & 65.9 \\
\hline Never married & 86 & 28.2 \\
\hline Other & 18 & 5.9 \\
\hline \multicolumn{3}{|l|}{ Currently living with spouse/partner } \\
\hline Yes & 199 & 65.3 \\
\hline No & 106 & 34.8 \\
\hline \multicolumn{3}{|l|}{ Country where born } \\
\hline Kosovo & 294 & 100.0 \\
\hline \multicolumn{3}{|l|}{ Years lived in Kosovo } \\
\hline $20 \mathrm{yr}$ or longer & 279 & 91.2 \\
\hline $10-19 \mathrm{yr}$ & 24 & 7.8 \\
\hline Less than $10 \mathrm{yr}$ & 3 & 1.0 \\
\hline \multicolumn{3}{|l|}{ Physically hurt in the war } \\
\hline Yes & 39 & 12.8 \\
\hline No & 267 & 87.2 \\
\hline \multicolumn{3}{|l|}{ Left Kosovo during the war } \\
\hline Yes & 175 & 57.6 \\
\hline No & 129 & 42.4 \\
\hline \multicolumn{3}{|c|}{ Live in same house as before the war } \\
\hline Yes & 173 & 56.9 \\
\hline No & 131 & 43.1 \\
\hline \multicolumn{3}{|c|}{ Any DSM-III-R posttraumatic stress symptom } \\
\hline Yes & 274 & 89.5 \\
\hline No & 32 & 10.5 \\
\hline \multicolumn{3}{|l|}{ Experienced any traumatic events } \\
\hline Yes & 296 & 97.4 \\
\hline No & 8 & 2.6 \\
\hline
\end{tabular}

experienced also was associated with higher posttraumatic stress scores $(\beta=0.04$; intercept $=1.74 ; p<.001)$. Social support had a protective association with the posttraumatic stress score in a bivariate model $(\beta=-0.11$; intercept $=$ $2.33 ; p=.01)$. 
TABLE 2. Traumatic Events Experienced by Gender, Kosovo Emergency Department Study, 2001; N=306

\begin{tabular}{|c|c|c|c|}
\hline Experience & $\begin{array}{c}\text { Percent } \\
\text { experienced }\end{array}$ & $\begin{array}{l}\text { Percent women } \\
\text { experienced }\end{array}$ & $\begin{array}{l}\text { Percent men } \\
\text { experienced }\end{array}$ \\
\hline Lack of food or water & 71.0 & 70.9 & 71.0 \\
\hline Lack of shelter & 65.5 & 73.6 & $60.8 * *$ \\
\hline Imprisonment & 12.2 & 2.7 & $17.6 * * *$ \\
\hline Serious injury & 13.5 & 4.6 & $18.6 * * * *$ \\
\hline Rape or sexual assault & 0.0 & 0.0 & 0.0 \\
\hline Forced isolation & 43.6 & 43.6 & 43.5 \\
\hline Being close to death & 46.2 & 43.1 & 47.9 \\
\hline Forced separation of family members & 55.3 & 55.1 & 55.5 \\
\hline Murder of family or friend & 31.4 & 34.9 & 29.4 \\
\hline Torture & 44.4 & 40.0 & 46.9 \\
\hline Other frightening or life endangering situation & 49.7 & 45.4 & 52.1 \\
\hline $\begin{array}{l}* p<.1 \\
* * p<.05 \\
* * * p<.01 \\
* * * * p<.001 \text { (two-tailed } \chi^{2} \text { test by gender). }\end{array}$ & & & \\
\hline
\end{tabular}

In a multivariable linear regression, adjusting for education and age, female gender $(\beta=0.15 ; p=.01)$, social support $(\beta=-0.09 ; p=.02)$, and sum of traumatic events experienced $(\beta=0.04 ; p<.001)$ were all still associated with the posttraumatic stress symptom score (Table 3 , model

TABLE 3. Multivariable Linear Regression Models Predicting Posttraumatic Stress Symptom Scores, Kosovo Emergency Department Study, 2001; $N=306$

\begin{tabular}{lcccc}
\hline Parameter & $\boldsymbol{\beta}$ & SE & $\boldsymbol{\beta}$ & SE \\
\hline Intercept & $1.71^{* * * *}$ & 0.16 & $1.50^{* * * *}$ & 0.17 \\
Female & $0.15^{* *}$ & 0.06 & $1.07 * * *$ & 0.33 \\
Social support & $-0.09^{* *}$ & 0.04 & -0.05 & 0.04 \\
Sum of traumatic events & $0.04^{* * * *}$ & 0.01 & $0.05^{* * * *}$ & 0.01 \\
High school education & -0.09 & 0.06 & -0.09 & 0.06 \\
Age & $0.007^{* * * *}$ & 0.002 & $0.007^{* * * *}$ & 0.002 \\
Social support times & & & $-0.23^{* *}$ & 0.09 \\
$\quad$ female & & & & \\
Traumatic events times & & & $-0.03^{*}$ & 0.02 \\
$\quad$ female & & & & \\
\hline$* p<.1$. & & & \\
$\quad * * p<.05$. & & & & \\
$\quad * * * p<.01$. & & & & \\
& & & & \\
\hline
\end{tabular}

1). The $r^{2}$ for this model was 0.21 . The addition of two interaction terms improved the model fit $(F$-test $p=.02)$. There was an interaction $(p<.2)$ between social support and female gender $(\beta=-0.23 ; p=.01)$ and an interaction between traumatic events experienced and female gender $(\beta=-0.03 ; p=.06$; Table 3 , model 2$)$. There was no interaction between social support and the sum of traumatic events. The $r^{2}$ for the final model was 0.23 .

Predicted values of the posttraumatic stress score for men and women with different levels of social support and traumatic events experienced, based on the final model with interactions, are presented in Figure 1. Among men with high social support (score of 4), those who experienced few traumatic events (one) had a predicted posttraumatic stress score of 1.58 (95\% CI, 1.41-1.76), and those who experienced many (13) had a predicted score of 2.19 (95\% CI, 2.00-2.37). For women with high social support and few traumatic events, the predicted posttraumatic stress score was 1.70 (95\% CI, 1.49-1.92); for women with high social support and many traumatic events, it was 1.91 (95\% CI, 1.64-2.19). Figure 1 also shows the predicted values for those with low social support (score of 1). Among men with low social support, those with few traumatic events had a predicted posttraumatic stress score of 1.72 (95\% CI, 1.50$1.95)$, and those with many traumatic events had a predicted 


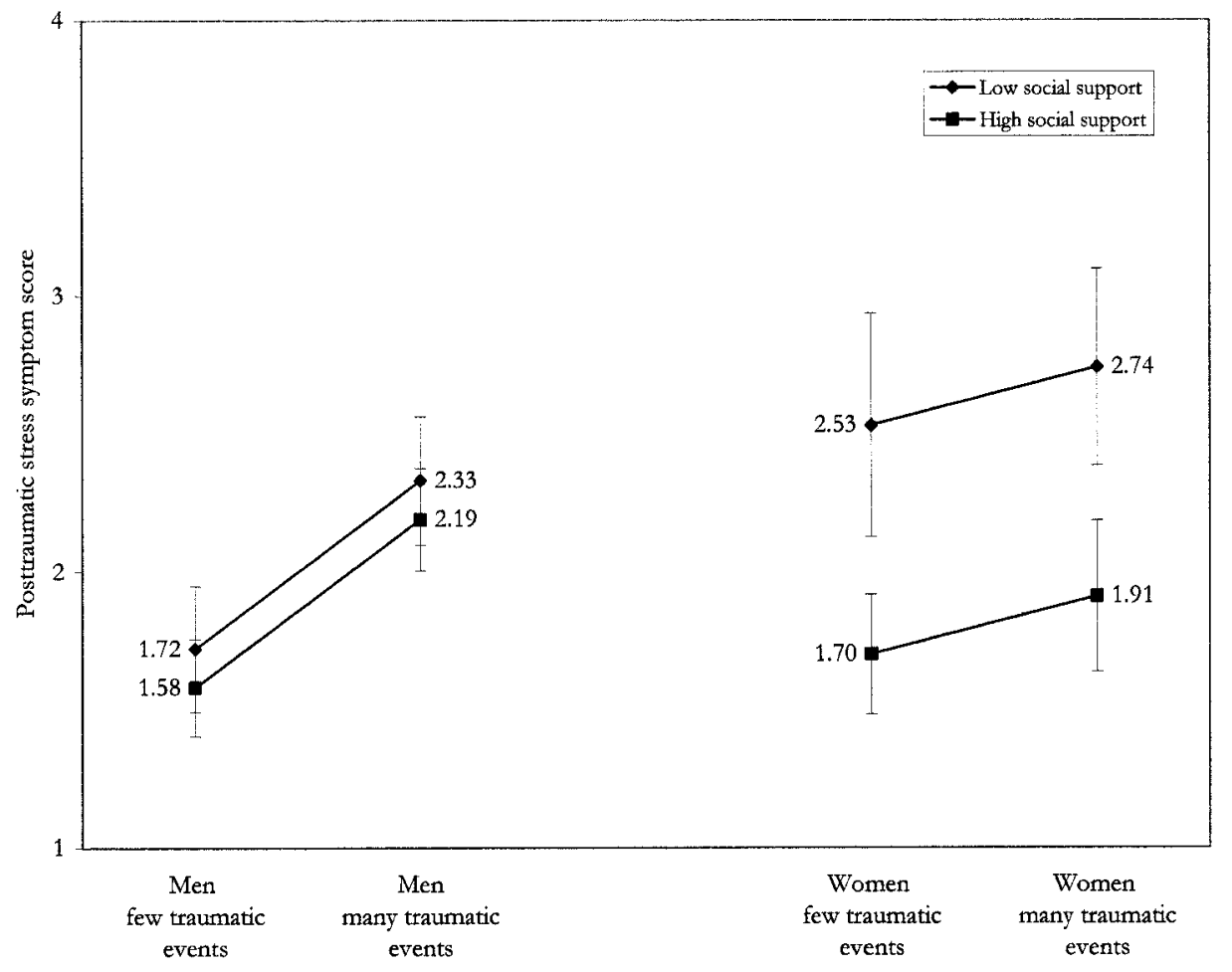

FIGURE 1. Predicted posttraumatic stress symptom scores and $95 \% \mathrm{Cls}$ by social support, traumatic events, and gender, Kosovo Emergency Department Study, 2001 score of 2.33 (95\% CI, 2.09-2.56). Among women with low social support, the predicted posttraumatic stress score was 2.53 (95\% CI, 2.12-2.93) for those with few traumatic events, and the predicted score was 2.74 (95\% CI, 2.38-3.10) for those with many traumatic events.

\section{DISCUSSION}

In this study of Kosovar Albanians presenting to a local emergency department, we found that 2 years after the end of the conflict in Kosovo, posttraumatic stress symptoms were still highly prevalent. Women had more posttraumatic stress symptoms than men, especially women with low social support. The number of different types of traumatic events experienced had a greater effect on men than it did on women. These findings have implications for how we think about the effects of trauma in the context of gender, because the groups at risk for longer-term psychological symptoms were different by gender.

We found a prevalence of $14.1 \%$ of probable PTSD in this emergency department sample, slightly lower than the prevalence documented by Cardozo et al. (2000) 2 years earlier in a general population sample. That study found a PTSD prevalence of $17.1 \%$ among the general population of Kosovar Albanians using the same PTSD measurement scale (Cardozo et al., 2000). Although these figures are not directly comparable because of the differences in the samples, the findings suggest there may still be a substantial burden of
PTSD symptoms 2 years after NATO bombing. This may be attributable in part to a continuing state of tension and conflict in Kosovo despite the official end to the war (United Nations Security Council, 2001), and in part to the higher prevalence of mental health symptoms that may be present in our emergency department-based sample (Kroenke et al., 1994). The types and prevalence of traumatic events experienced in this population were similar to other studies conducted in postwar settings. The proportions of respondents reporting lack of food or water $(71.0 \%$ compared with $66.6 \%$ in Cardozo et al., 2000), lack of shelter (65.5\% compared with $57.3 \%$ in Cardozo et al., 2000), experiencing eight or more traumatic events (44.1\% compared with $39.4 \%$ in Cardozo et al., 2000), and other experiences were similar between the studies (Cardozo et al., 2000). The prevalence of traumatic events documented in this study is generally similar to other studies in war and refugee settings, although the use of different scales between studies precludes direct comparison. In a study of Bosnian refugees, respondents in the general population had an average of 6.31 loss experiences and 1.90 violence experiences, which combined is slightly higher than the total of 6.62 traumatic events experienced in our sample (Miller et al., 2002). Shortly after the civil war in Croatia, a general population study found that the proportions of respondents who had relatives or friends killed were $13.7 \%$ and $20.8 \%$, respectively (Kunovich, 1999). These proportions are somewhat lower than our findings of $31.4 \%$ of respondents 
reporting a family member or friend murdered and $25.1 \%$ reporting a family member or friend suffering an unnatural death. The level of exposure to combat was higher in this study $(92.7 \%$ experienced a combat situation, $96.3 \%$ of women, $90.7 \%$ of men) compared with two studies among women in Beirut, Lebanon; in one study, $73.7 \%$ of respondents had experienced fighting in the neighborhood (Bryce et al., 1989), and in the other, $41 \%$ had armed clashes in the neighborhood (Farhood et al., 1993). Combat exposure in this study was very similar to two studies of women in Bosnia, one of which found that $90 \%$ of respondents had experienced war activities (Dybdahl, 2001), and the other of which found that $84 \%$ of women had been in situations in which they felt their lives had been endangered (Dahl et al., 1998).

Respondents in this study reported a range of levels of social support, with an average of middle to high support, similar to findings in other studies in the postwar context. In a study of internally displaced mothers in Bosnia, the social support scores were approximately 4 to 5 out of 7 on average for various types of support (Dybdahl, 2001). In a study of Lebanese families, among both mothers and fathers, $70 \%$ to $90 \%$ of respondents reported satisfaction with social support for a variety of types of problems (Farhood et al., 1993).

We found higher posttraumatic stress scores among women compared with men, and higher prevalence of probable PTSD among women, although this difference was not statistically significant. Cardozo et al. (2000) found PTSD levels of $19.7 \%$ among women and $12.0 \%$ among men in Kosovo in 1999. Some research suggests that men may manifest traumatization in different ways than women, possibly through substance use (Gibbs, 1989; Somasundaram and Sivayokan, 1994; Stewart, 1996). In our study, $20.7 \%$ of men were current drinkers, compared with $3.7 \%$ of women, but only $2.5 \%$ of men reported having more than two drinks per day. Although alcohol use was quite low in this sample, there was more drinking among men, suggesting that gender differences in substance use as a response to disaster or war warrant further research.

We found that social support was more strongly protective against traumatization among women than among men, evidenced by the dramatic difference in posttraumatic stress symptoms between women with high and low social support. The predicted posttraumatic stress scores for women with low social support indicated that they were bothered "quite a bit" by the majority of PTSD symptoms in the past week, whereas women with high social support were bothered only "a little" by the majority of symptoms. These findings suggest that in the postconflict situation, women with low social support have posttraumatic stress symptoms that are a cause for concern. We are aware of only two studies in conflict situations that looked at this same question among both women and men. The first, a study among married couples with children in Lebanon, found that social support was more strongly associated with measures of psychologi- cal, physical, and interpersonal health for the fathers than for the mothers (Farhood et al., 1993). This is in contrast to our findings. The observed difference in findings may relate to the different societal contexts and the ways that gender roles have been affected by these conflicts (Kunovich, 1999). In addition, one of the strongest predictors of psychological symptoms among mothers in the Lebanon study was the intention of the family to move within or migrate from Lebanon (Farhood et al., 1993). Among other consequences, moving would likely disrupt established social ties, which may be more important for women than the current satisfaction with such ties. The authors also note that the majority of mothers in their study were housewives and suggest that these mothers may be isolated more than the fathers, who were able to maintain relationships through work (Farhood et al., 1993). There may not have been sufficient variability in social network among the mothers for the study to observe an association with the heath measures (Farhood et al., 1993). The second study examined male and female Vietnam veterans in the United States using structural equation modeling to examine the relative importance of war zone stressors, postwar recovery factors (including social support), and prewar risk factors in predicting PTSD (King et al., 1999). More congruent with our observations, this analysis found that war zone stressors were the strongest predictors of PTSD symptomatology among male veterans, whereas postwar factors including social support were the most important in explaining PTSD among female veterans (King et al., 1999). There is some additional support for our findings in studies limited to one gender (Dybdahl, 2001; Green and Berlin, 1987). A study of mothers in Bosnia showed that higher social support was protective against PTSD symptoms (Dybdahl, 2001), whereas a study among male Vietnam veterans showed that social support was not associated with PTSD symptoms (Green and Berlin, 1987).

In this analysis, the number of types of traumatic events experienced was more strongly associated with the posttraumatic stress score for men than it was for women. This difference is consistent with a study in Croatia in which the association between fighting in the war and distress was stronger among men than it was among women (Kunovich, 1999). It is also consistent with a study among mothers in Bosnia in which the number of traumatic events experienced was not associated with PTSD symptoms (Dybdahl, 2001). However, it is contrary to a study among Lebanese women finding that the number of war experiences was associated with depression (Bryce et al., 1989). Differences in mental health measures and qualitative and cultural differences in conflict situations may explain the heterogeneity of results. Additionally, ubiquitous experiences of traumatic events in some combat situations may mean that number of events experienced does not fully differentiate between levels of traumatization experienced. 
The clinical sample used in this analysis may not represent the general population of Kosovar Albanians, because persons who present to an emergency department may have a greater burden of pathology than persons in the general population. Selection bias is also a potential problem if the men and women who presented to the emergency department were not representative of the men and women in the general population of Kosovar Albanians in terms of the relationships between social support, traumatic experiences, and psychological symptoms. We did not assess the number of times each traumatic event was experienced, which may be an important dimension that affects levels of traumatization. We also do not have information on the recency of these experiences. Current daily stressors were not measured in this study. They have been shown to affect mental health, even in the war context, in addition to the war stressors (Farhood et al., 1993; Miller et al., 2002). We did not measure social support provided to others, which may be a drain on mental resources and is more commonly provided by women (Kawachi and Berkman, 2001). We also do not have a measure of social support at the time of the conflict, which may be important to determining the course of posttraumatic stress symptoms. In addition, although we found that $79.1 \%$ of our respondents had heard of rape or sexual assault, there were no reports of rape or sexual assault experienced in this study. This traumatic experience may not have been reported because respondents were unwilling to reveal this experience. Rape is strongly associated with PTSD symptomatology among women in other studies (Breslau et al., 1999; Dahl et al., 1998; Kessler et al., 1995), and underreporting may partly explain the weaker association between traumatic events and posttraumatic stress among women in this study. It is also possible that within particular traumatic events reported, there are differences in the specifics of those experiences by gender. For example, both men and women reported "being in a combat situation"; however, we do not have further information on their roles in those combat situations. These differences may contribute to the weaker association between traumatic events and posttraumatic stress among women.

\section{CONCLUSION}

This study suggests that social support and gender are important factors to consider when examining traumatic event experiences and posttraumatic stress symptoms. Two years after the end of the conflict in Kosovo, there was a substantial burden of posttraumatic stress in this emergency department sample, particularly among women with low social support. The war in Kosovo has led to an increase in women heads of household, and many women are isolated in rural areas (Munzer, 2002). ${ }^{l}$ Although many women may

\footnotetext{
${ }^{1}$ Munzer C (2002) Kosovo Women's Initiative Coordinator, International Rescue Committee Kosovo. Personal communication.
}

have assumed greater responsibilities, they do not have equal access to resources, because they are generally not included as part of the decision-making process in community and government arenas (Munzer, 2002). In this context, support for women is a major concern. Some studies suggest that interventions with women and families may be effective in postwar situations at increasing perceived social support and improving mental health (Dybdahl, 2001; Kawachi and Berkman, 2001; Miller et al., 2002; Tribe and Silva, 1999; Weine et al., 1998). One initiative in Kosovo, the Kosovar Family Professional Education Collaborative, has been addressing mental health in the context of the family (Weine, 2001), which may be important for rebuilding supports that have been lost because of the conflict. Interventions that build social support, especially among families and among women, may be important public health efforts in the postwar context.

\section{ACKNOWLEDGMENTS}

The authors thank Drs. Julian Lis, Michael VanRooyen, and Brett Nelson for logistical assistance.

\section{REFERENCES}

Agani F (2001) Mental health challenges in postwar Kosova. JAMA. 285: 1217.

Berkman LF, Glass T, Brissette I, Seeman TE (2000) From social integration to health: Durkheim in the new millennium. Soc Sci Med. 51:843-857.

Breslau N, Chilcoat HD, Kessler RC, Peterson EL, Lucia VC (1999) Vulnerability to assaultive violence: Further specification of the sex difference in post-traumatic stress disorder. Psychol Med. 29:813-821.

Brewin CR, Andrews B, Valentine JD (2000) Meta-analysis of risk factors for posttraumatic stress disorder in trauma-exposed adults. $J$ Consult Clin Psychol. 68:748-766.

Bryce JW, Walker N, Ghorayeb F, Kanj M (1989) Life experiences, response styles and mental health among mothers and children in Beirut, Lebanon. Soc Sci Med. 28:685-695.

Bultmann U, Kant IJ, Van den Brandt PA, Kasl SV (2002) Psychosocial work characteristics as risk factors for the onset of fatigue and psychological distress: Prospective results from the Maastricht cohort study. Psychol Med. 32:333-345.

Cardozo BL, Vergara A, Agani F, Gotway CA (2000) Mental health, social functioning and attitudes of Kosovar Albanians following the war in Kosovo. JAMA. 284:569-577.

Dahl S, Mutapcic A, Schei B (1998) Traumatic events and predictive factors for posttraumatic symptoms in displaced Bosnian women in a war zone. J Trauma Stress. 11:137-145.

de Jong JTVM, Komproe IH, Ommeren MV, Masri ME, Araya M, Khaled N, van de Put W, Somasundaram D (2001) Lifetime events and posttraumatic stress disorder in 4 postconflict settings. JAMA. 286:555-562.

Dybdahl R (2001) Children and mothers in war: An outcome study of a psychosocial intervention program. Child Dev. 72:1214-1230.

Engdahl B, Dikel TN, Eberly R, Blank A (1997) Posttraumatic stress disorder in a community group of former prisoners of war: A normative response to severe trauma. Am J Psychiatry. 154:1576-1581.

Farhood L, Zurayk H, Chaya M, Saadeh F, Meshefedjian G, Sidani T (1993) The impact of war on the physical and mental health of the family: The Lebanese experience. Soc Sci Med. 36:1555-1567.

Gibbs MS (1989) Factors in the victim that mediate between disaster and psychopathology. J Trauma Stress. 2:489-514.

Green MA, Berlin MA (1987) Five psychosocial variables related to the existence of post-traumatic stress disorder symptoms. J Clin Psychol. 43:643-649.

Hauff E, Vaglum P (1995) Organized violence and the stress of exile, 
predictors of mental health in a community cohort of Vietnamese refugees three years after resettlement. Br J Psychiatry. 166:360-367.

Kawachi I, Berkman LF (2001) Social ties and mental health. $J$ Urban Health. 78:458-467.

Kessler RC, Sonnega A, Bromet E, Hughes M, Nelson CB (1995) Posttraumatic stress disorder in the National Comorbidity Survey. Arch Gen Psychiatry. 52:1048-1060.

King DW, King LA, Foy DW, Keane TM, Fairbank JA (1999) Posttraumatic stress disorder in a national sample of female and male Vietnam veterans: Risk factors, war-zone stressors and resilience-recovery variables. $J \mathrm{Ab}$ norm Psychol. 108:164-170.

Kroenke K, Spitzer RL, Williams JB, Linzer M, Hahn SR, deGruy FV, Brody D (1994) Physical symptoms in primary care: Predictors of psychiatric disorders and functional impairment. Arch Fam Med. 3:774-779.

Kunovich RM (1999) Civil war, social integration and mental health in Croatia. $J$ Health Soc Behav. 40:323-343.

Miller KE, Weine SM, Ramic A, Brkic N, Bjedic ZD, Smajkic A, Boskailo E, Worthington G (2002) The relative contribution of war experiences and exile-related stressors to levels of psychological distress among Bosnian refugees. J Trauma Stress. 15:377-387.

Mollica RF, Caspi-Yavin Y, Bollini P, Truong T, Tor S, LaVelle J (1992) The Harvard Trauma Questionnaire, validating a cross-cultural instrument for measuring torture, trauma and posttraumatic stress disorder in Indochinese refugees. J Nerv Ment Dis. 180:111-116.

Mollica RF, McInnes K, Sarajlic N, LaVelle J, Sarajlic I, Massagli MP (1999) Disability associated with psychiatric comorbidity and health status in Bosnian refugees living in Croatia. JAMA. 282:433-439.

Mollica RF, Wyshak G, Khoun F, LaVelle J (1987) Indochinese versions of the Hopkins Symptom Checklist. Am J Psychiatry. 144:497-500.

Olstad R, Sexton H, Sogaard AJ (2001) The Finnmark study: A prospective population study of the social support buffer hypothesis, specific stressors and mental distress. Soc Psychiatry Psychiatr Epidemiol. 36:582-589.

Sherbourne CD, Stewart AL (1991) The MOS social support survey. Soc Sci Med. 32:705-714.

Silveira ER, Ebrahim S (1998) Social determinants of psychiatric morbidity and well-being in immigrant elders and whites in east London. Int $J$ Geriatr Psychiatry. 13:801-812.

Solomon Z, Margalit C, Waysman M, Bleich A (1991) In the shadow of the Gulf War: Psychological distress, social support and coping among Israeli soldiers in a high risk area. Isr J Med Sci. 27:687-695.

Somasundaram DJ, Sivayokan A (1994) War trauma in a civilian population. Br J Psychiatry. 165:524-527.

Stein MB (2000) Gender differences in susceptibility to posttraumatic stress disorder. Behav Res Ther. 38:619-628.

Stewart SH (1996) Alcohol abuse in individuals exposed to trauma: A critical review. Psychol Bull. 120:83-112.

Tribe R, Silva PD (1999) Psychological intervention with displaced widows in Sri Lanka. Int Rev Psychiatry. 11:184-190.

United Nations Security Council (2001) Report of the secretary-general on the United Nations interim administration mission in Kosovo, www. un.org/Docs/sc/reports/2001/sgrep01.htm.

Viinamaki H, Kontula O, Niskanen L, Koskela K (1995) The association between economic and social factors and mental health in Finland. Acta Psychiatr Scand. 92:208-213.

Weine S (2001) From war zone to contact zone: Culture and refugee mental health services. JAMA. 285:1214.

Weine S, Vojvoda D, Becker D, McGlachan T, Hodzic E, Laub D, Hyman L, Sawyer M, Lazrove S (1998) PTSD symptoms in Bosnian refugees 1 year after resettlement in the United States. Am J Psychiatry. 155:562564. 